\title{
The Investigation of Adsorption Behavior of Gas Molecules on $\mathrm{FeN}_{\mathbf{3}}$-Doped Graphene
}

\author{
Tingyue Xie $\mathbb{D}^{1,2}$, Ping Wang $\mathbb{D}^{2}$ Cuifeng Tian $\mathbb{D}^{2},{ }^{2}$ Guozheng Zhao $\mathbb{D}^{1},{ }^{1}$ Jianfeng Jia $\mathbb{D},{ }^{1}$ \\ Chaozheng $\mathrm{He}\left(\mathbb{D},{ }^{3}\right.$ Chenxu Zhao $\mathbb{D}^{3},{ }^{3}$ and Haishun $\mathrm{Wu} \mathbb{D}^{1}$ \\ ${ }^{1}$ School of Chemistry and Materials Science of Shanxi Normal University, Key Laboratory of Magnetic Molecules and Magnetic \\ Information Materials of Ministry of Education, Linfen 041004, China \\ ${ }^{2}$ School of Physical and Electronics Science, Shanxi Datong University, Datong 037009, China \\ ${ }^{3}$ Institute of Environmental and Energy Catalysis, School of Materials Science and Chemical Engineering, \\ Xi'an Technological University, Xi'an, Shaanxi 710021, China
}

Correspondence should be addressed to Chenxu Zhao; zhaochenxu@xatu.edu.cn and Haishun Wu; wuhs@sxnu.edu.cn

Received 27 October 2021; Revised 9 January 2022; Accepted 17 January 2022; Published 29 January 2022

Academic Editor: Carlos Michel

Copyright (C) 2022 Tingyue Xie et al. This is an open access article distributed under the Creative Commons Attribution License, which permits unrestricted use, distribution, and reproduction in any medium, provided the original work is properly cited.

\begin{abstract}
Herein, we have investigated the adsorption behavior of gas molecules, including $\mathrm{C}_{2} \mathrm{H}_{2}, \mathrm{H}_{2} \mathrm{~S}, \mathrm{SO}_{2}, \mathrm{SO}_{3}$, and $\mathrm{O}_{2}$, on $\mathrm{FeN}_{3}$-doped graphene $\left(\mathrm{FeN}_{3}\right.$-gra). The change of geometric stability, electric structure, and magnetic properties is discussed comprehensively. The results have demonstrated that the stability of the substrate is enhanced by the hybridization between Fe and $\mathrm{N}$ atoms in $\mathrm{FeN}_{3}$-gra. Besides, the Fe dopant can enhance the adsorption ability of gases on graphene. The gas molecules all exhibit high binding strength on $\mathrm{FeN}_{3}$-gra especially for $\mathrm{SO}_{3}$ with the adsorption energy of $-3.30 \mathrm{eV}$. The mechanism of interaction between gases and substrate is investigated based on the charge density difference and density of states, which can clarify the distribution of electrons and magnetic moments. Moreover, the high stability and sensitivity of FeN ${ }_{3}$-gra are promising characters for gas detection. Our research has paved the way for the application of the graphene-based material in gas sensor and electronic instrument.
\end{abstract}

\section{Introduction}

The air pollution caused by the emission of poison gases has attracted global attention in recent years. For example, the gases, such as $\mathrm{C}_{2} \mathrm{H}_{2}, \mathrm{H}_{2} \mathrm{~S}, \mathrm{SO}_{2}, \mathrm{SO}_{3}$, and $\mathrm{O}_{2}$, can harm the health of human beings in our daily life. Among these gases, $\mathrm{SO}_{2}$ and $\mathrm{SO}_{3}$ are the general inducement of acid rain [1]; $\mathrm{H}_{2} \mathrm{~S}$ is a kind of combustible gas with no colour [2]; $\mathrm{C}_{2} \mathrm{H}_{2}$ is a gas with a little poison for cells in the human body [3]; the gas sensor can be used to detect inflammable and poison gases and has been applied extensively into areas including industry and fire control [4]. Based on this basic model, many works have also been performed on the gas capture and catalysis [2, 3, 5-8]. The commonly used adsorbates mainly include metals, metal oxides, and graphene-based materials. The graphene-based single-atom catalysts (SACgra) have been extensively applied into gas sensor due to the merits including low cost, high conductivity, perfect chemical stability, big specific surface area, and high mechanical strength [9-11]. Most importantly, the electric properties of substrates can be changed under the influence of molecule adsorption, which mainly originates from the charge transfer between molecules and the substrates [12]. Thus, graphene is a promising candidate in gas sensor [13-15]. In some experimental works, the graphene has been made into some devices of gas sensors with high sensitivity $[16,17]$, which has great significance for establishing early warning systems.

The transition metals (TMs) and $\mathrm{N}$ atoms are commonly used dopants in graphene-based SAC, which play an important role in catalytic reactivity [18-23]. The Fe SAC based on $\mathrm{N}$-doped graphene has been proved to possess remarkable reactivity in pioneering works [24]. Thus, the $\mathrm{N}$ coordinated SAC-gra has been extensively investigated by 
scientists to find out the effective candidates for electric catalysts [25-27]. For example, the first-principle investigation of $\mathrm{N}_{2}$ adsorption on $\mathrm{FeN}_{3}$-doped graphene ( $\mathrm{FeN}_{3}$-gra) has been performed and the results demonstrate that the catalyst can activate $* \mathrm{~N}$ to $* \mathrm{NH}$ with high efficiency [28]. Liu et al. have also investigated the degradation of $\mathrm{CH}_{2} \mathrm{O}$ to $\mathrm{H}_{2} \mathrm{O}$ and $\mathrm{CO}_{2}$ on $\mathrm{FeN}_{3}$-gra, indicating that the desorption process of the reaction products is advantageous in this system [29]. However, the reports on the gases, including $\mathrm{C}_{2} \mathrm{H}_{2}, \mathrm{H}_{2} \mathrm{~S}$, $\mathrm{SO}_{2}, \mathrm{SO}_{3}$, and $\mathrm{O}_{2}$, are limited on $\mathrm{FeN}_{3}$-gra.

Herein, we have performed calculations based on density functional theory (DFT) on $\mathrm{FeN}_{3}$-gra, including geometric configurations, stability, and origin of magnetic. In addition, the adsorption of gas molecules, including $\mathrm{C}_{2} \mathrm{H}_{2}, \mathrm{H}_{2} \mathrm{~S}, \mathrm{SO}_{2}$, $\mathrm{SO}_{3}$, and $\mathrm{O}_{2}$, has also been studied on $\mathrm{FeN}_{3}$-gra. The calculations are mainly focused on the change of configurations, charge density, and spin states influenced by the interaction between gas molecules and substrates. The intrinsic mechanism has also been analyzed via density of states (DOS). Our results may pave the way for development of gas sensor on both experimental and theoretical aspects.

\section{Computational Methods}

In this work, the first-principle calculations are carried out based on density functional theory (DFT) in the Vienna ab initio simulation package (VASP). Exchange and correlation potential is illustrated by the projector augmented wave (PAW) $[30,31]$ and the generalized gradient approximation (GGA) in format [32-34]. The interaction of the van der Waals (vdW) is employed with DFT-D3 [35]. Other geometric and physical parameters are described in detail in our previous work [36]. The charge transfer characteristics between FeN3-gra and the catalysts are evaluated by the Bader charge [37].

The binding energy of single Fe atom $\left(E_{\mathrm{b}}[\mathrm{Fe}]\right)$ in $\mathrm{Fe} / \mathrm{N}_{3}$ gra is expressed as

$$
E_{\mathrm{b}}[\mathrm{Fe}]=E[\mathrm{Fe}]+E\left[\mathrm{~d}-\mathrm{Fe} / \mathrm{N}_{3}-\text { gra }\right]-E\left[\mathrm{Fe} / \mathrm{N}_{3}-\text { gra }\right],
$$

where the $E\left[\mathrm{Fe} / \mathrm{N}_{3}-\right.$ gra $], E\left[\mathrm{~d}-\mathrm{Fe} / \mathrm{N}_{3}-\right.$ gra $]$, and $E[\mathrm{Fe}]$ denote total energy of $\mathrm{Fe} / \mathrm{N}_{3}$-gra, $\mathrm{Fe} / \mathrm{N}_{3}$-gra with Fe vacancy, and single $\mathrm{Fe}$ atom in vacuum, respectively.

The adsorption energy of gas molecules $E_{\mathrm{ad}}[$ gas] on Fe/ $\mathrm{N}_{3}$-gra is expressed as

$$
E_{\mathrm{ad}}[\text { gas }]=E[\text { gas }]+E\left[\mathrm{Fe} / \mathrm{N}_{3}-\text { gra }\right]-E\left[\text { gas }-\mathrm{Fe} / \mathrm{N}_{3}-\text { gra }\right],
$$

where the $E\left[\right.$ gas $-\mathrm{Fe} / \mathrm{N}_{3}-$ gra $], E\left[\mathrm{Fe} / \mathrm{N}_{3}-\right.$ gra], and $E[$ gas $]$ denote total energy of gas adsorbed $\mathrm{Fe} / \mathrm{N}_{3}$-gra, $\mathrm{Fe} / \mathrm{N}_{3}$-gra surface, and single gas molecules in vacuum, respectively.

In addition, the electron density difference is visualized via VESTA3 [38].

\section{Results and Discussion}

3.1. The Configuration and Electric Properties of $\mathrm{FeN}_{3}$-gra. The configuration of $\mathrm{FeN}_{3}$-gra after full optimization is shown in Figure 1. The length of Fe-N bonds is $1.87 \AA$. The uplift height of $\mathrm{Fe}$ atom above graphene plane is about $1.47 \AA$, which can serve as an appropriate adsorption site [28]. In order to verify the stability of the configuration, the binding energy of $\mathrm{Fe}$ atom in the $\mathrm{FeN}_{3}$-gra is also calculated with a value of $4.97 \mathrm{eV}$, which is larger than the cohesive energy of Fe. This may indicate that the $\mathrm{N}$ atoms can bind $\mathrm{Fe}$ tightly enough to prohibit the aggregation of $\mathrm{Fe}$ atoms into clusters. Therefore, the $\mathrm{FeN}_{3}$-gra possesses strong geometric stability, which is beneficial for application in gas adsorbate. Table S1 has summarized the data of bond length, the uplift height of $\mathrm{Fe}$, charge, binding energies, and magnetic moments. The values calculated generally agree with the pioneering works, indicating the accuracy of our results [39].

It is worth noting that the charge transfer (CT) between $\mathrm{Fe}$ and $\mathrm{N}$ atoms in $\mathrm{FeN}_{3}$-gra is 0.96 e (Bader charge). However, the CT between Fe and adjacent $\mathrm{C}$ atoms in Fe-doped graphene with no $\mathrm{N}$ doping (Fe-gra) is only 0.69e [40]. Thus, $\mathrm{N}$ doping can lead to the formation of covalent bonds between $\mathrm{Fe}$ and the substrate. Besides, the $\mathrm{N}$ doping can also increase the magnetic moment from 0 (Fe-gra) to $3.17 \mu \mathrm{B}$ $\left(\mathrm{FeN}_{3}\right.$-gra), which further leads to a half-occupied state of the system $[41,42]$. In order to verify the magnetic character of $\mathrm{FeN}_{3}$-gra, the DOS has been calculated, showing an asymmetrical distribution between up and down spin, leading to a high magnetic moment (see Figure 2). There exists a strong overlap between Fe-3d states and total dos (TDOS) of $\mathrm{FeN}_{3}$ gra. This may indicate that the magnetic moments are mainly contributed by the $3 \mathrm{~d}$ states, which can be enhanced via the hybridization between $\mathrm{Fe}$ and $\mathrm{N}$ atoms. In order to further clarify the character of magnetism, we have also displayed the density of spin in Figures 1(c) and 1(d). The distribution of spin mainly concentrates on the Fe site, which agrees with the DOS.

3.2. The Adsorption Behavior of $\mathrm{C}_{2} \mathrm{H}_{2}$ and $\mathrm{H}_{2} \mathrm{~S}$. The optimal adsorption configurations of gas molecules are confirmed after comprehensive calculation of different adsorption orientations (see Figure S1).

We first focus our study on the adsorption of $\mathrm{C}_{2} \mathrm{H}_{2}$ and $\mathrm{H}_{2} \mathrm{~S}$ on $\mathrm{FeN}_{3}$-gra. For $\mathrm{C}_{2} \mathrm{H}_{2}$ adsorption, the C-C bond distributes nearly parallel to the $\mathrm{FeN}_{3}$-gra surface (see Figure S2). The bond angle and bond length of $\mathrm{C}_{2} \mathrm{H}_{2}$ have changed dramatically after adsorption, which is mainly caused by the strain around Fe dopant. The adsorption energy and adsorption distance are $2.23 \mathrm{eV}$ and $1.93 \AA$ (see Table S2), which agrees with the situation on Mn-doped graphene [43]. The Fe doping can also promote the charge transfer between gas molecules and substrates (see Table S2): the $\mathrm{C}_{2} \mathrm{H}_{2}$ and $\mathrm{H}_{2} \mathrm{~S}$ all act as electron acceptor and are negatively charged with $0.43 \mathrm{e}$ and $0.07 \mathrm{e}$, respectively (see Figure S3). For $\mathrm{H}_{2} \mathrm{~S}$ adsorption, $\mathrm{H}_{2} \mathrm{~S}$ tends to adsorb on the top site of $\mathrm{FeN}_{3}$-gra with an adsorption energy of $1.19 \mathrm{eV}$, which agrees with the pioneering works $[22,40]$. The bond length and bond angle of $\mathrm{H}_{2} \mathrm{~S}$ are similar as adsorbed on $\mathrm{FeN}_{3}$-gra and Fe-gra. Therefore, the $\mathrm{N}$ doping has nearly no influence on the adsorption behavior of $\mathrm{H}_{2} \mathrm{~S}$ (see Table S3) [22]. 


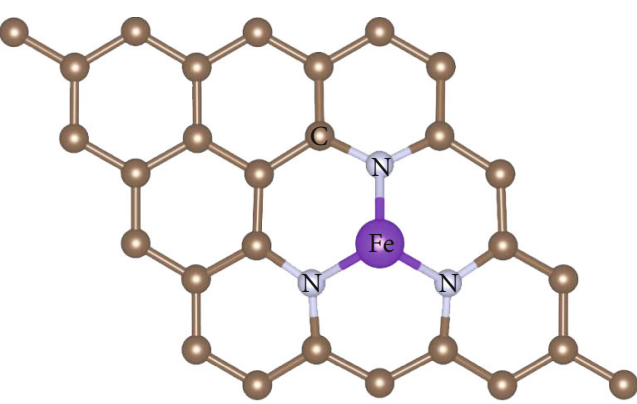

(a)

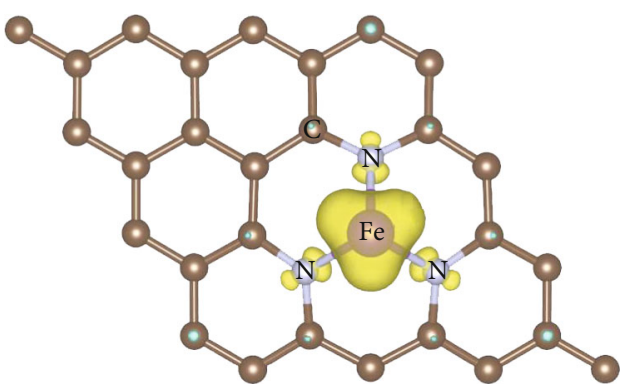

(c)

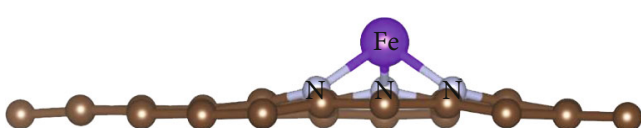

(b)

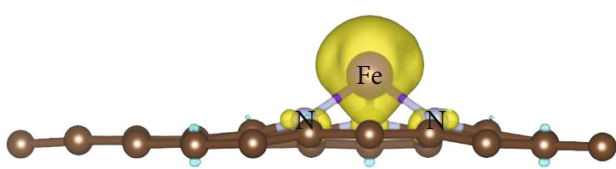

(d)

Figure 1: The top view (a) and side view (b) of $\mathrm{FeN}_{3}$-gra configuration; the top view (c) and side view (d) of the corresponding spin density distribution (spin up (yellow) and spin down (cyan); isosurface value: $0.01 \mathrm{e} / \mathrm{Bohr}^{3}$ ).

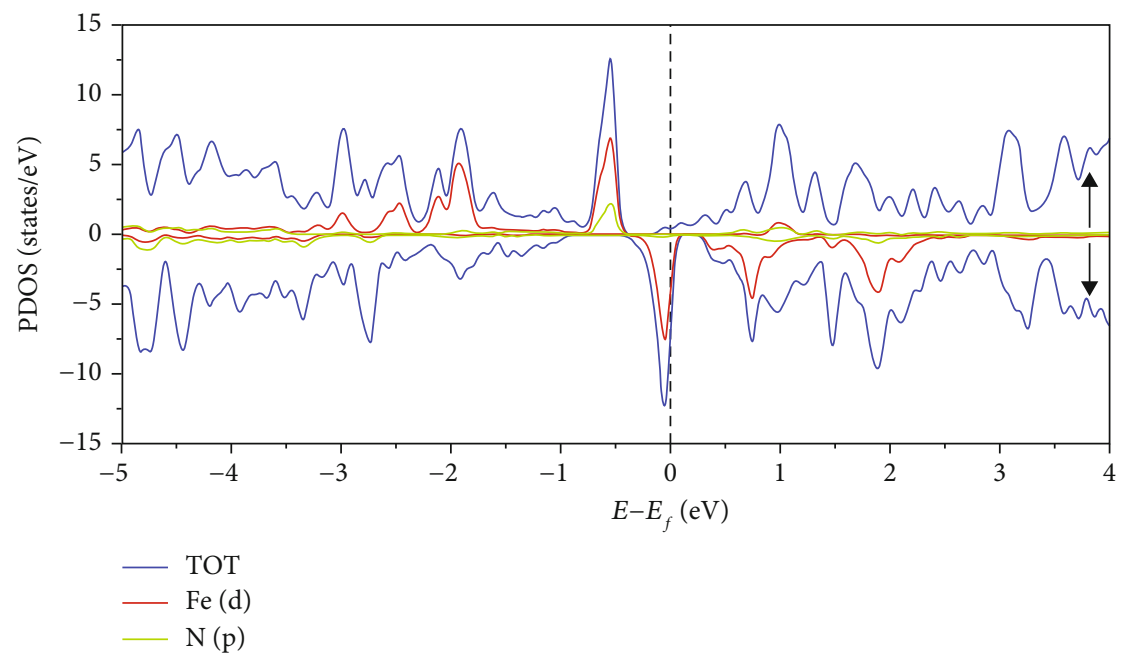

Figure 2: The partial density of states (PDOS) and total density of states (TDOS) of $\mathrm{FeN}_{3}$-gra. The arrow up and arrow down indicate the spin up and spin down states, respectively. The Fermi level is defined as $0 \mathrm{eV}$.

In order to clarify the adsorption behavior of $\mathrm{C}_{2} \mathrm{H}_{2}$ and $\mathrm{H}_{2} \mathrm{~S}$ on $\mathrm{FeN}_{3}$-gra, we have also calculated the partial density of state (PDOS). As shown in Figure 3(a), the distribution of Fe-3d states has become delocalized after $\mathrm{C}_{2} \mathrm{H}_{2}$ adsorption and hybridized with $\mathrm{C}_{2} \mathrm{H}_{2}$ 's orbitals dramatically near Fermi level. In addition, the spin states have also changed significantly with an increased magnetic moment of $3.02 \mu \mathrm{B}$ (see Table S2), which agrees with the spin density (see Figure S1 (a)). Therefore, the regulation of DOS near Fermi level can significantly change the electric and magnetic properties of $\mathrm{FeN}_{3}$-gra, which is beneficial for the application in spintronic devices.
In comparison, the hybridization between $\mathrm{H}_{2} \mathrm{~S}$ and $\mathrm{FeN}_{3}$-gra is much less than $\mathrm{C}_{2} \mathrm{H}_{2}$ situation, leading to a weaker adsorption ability of $\mathrm{H}_{2} \mathrm{~S}$. The $\mathrm{Fe}$ in $\mathrm{FeN}_{3}$-gra can form chemical bonds with $\mathrm{H}_{2} \mathrm{~S}$ (see Figure S3 (b)), which agrees with PDOS analysis. Similar to $\mathrm{C}_{2} \mathrm{H}_{2}$, the spin states of $\mathrm{H}_{2} \mathrm{~S} / \mathrm{FeN}_{3}$-gra complex has changed significantly for both up and down spins compared to bare $\mathrm{FeN}_{3}$-gra (see Figure 3(b)), leading to a total magnetic moment of $3.24 \mu \mathrm{B}$. The increased spin state originates from the charge transfer from $\mathrm{FeN}_{3}$-gra to $\mathrm{H}_{2} \mathrm{~S}$, leading to a decreased electric energy of $\mathrm{H}_{2} \mathrm{~S}$. The spin states are strongly localized on $\mathrm{Fe}$ site in $\mathrm{FeN}_{3}$-gra (Figure $\mathrm{S} 1$ (b)). 

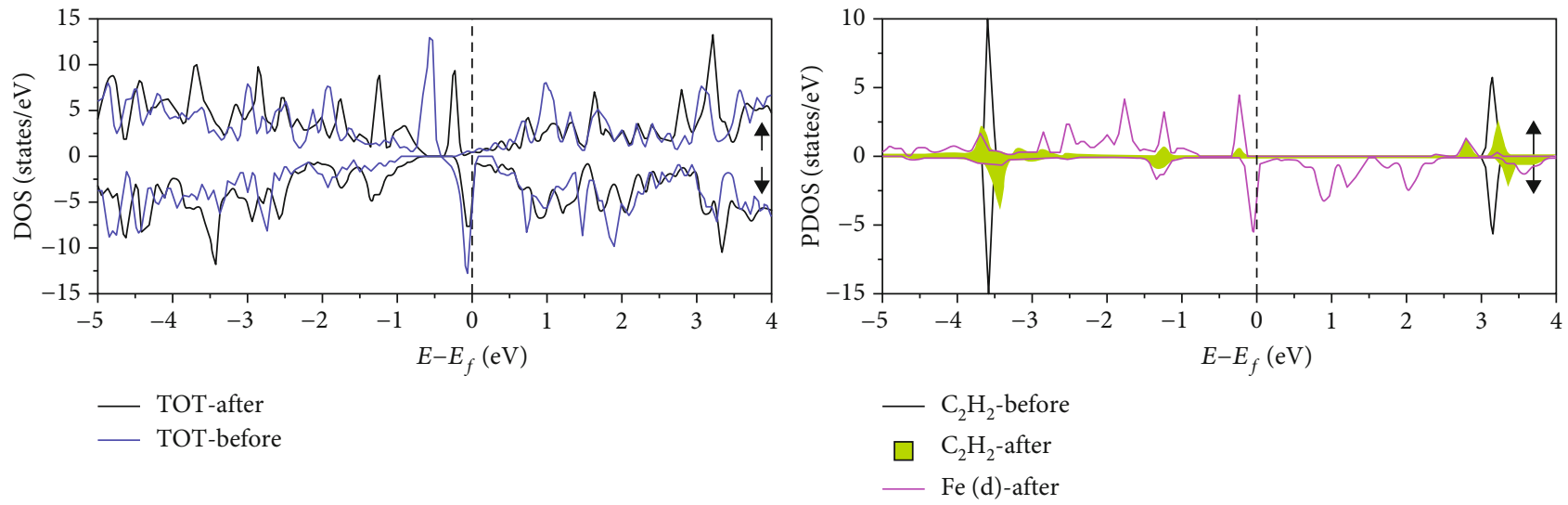

(a)
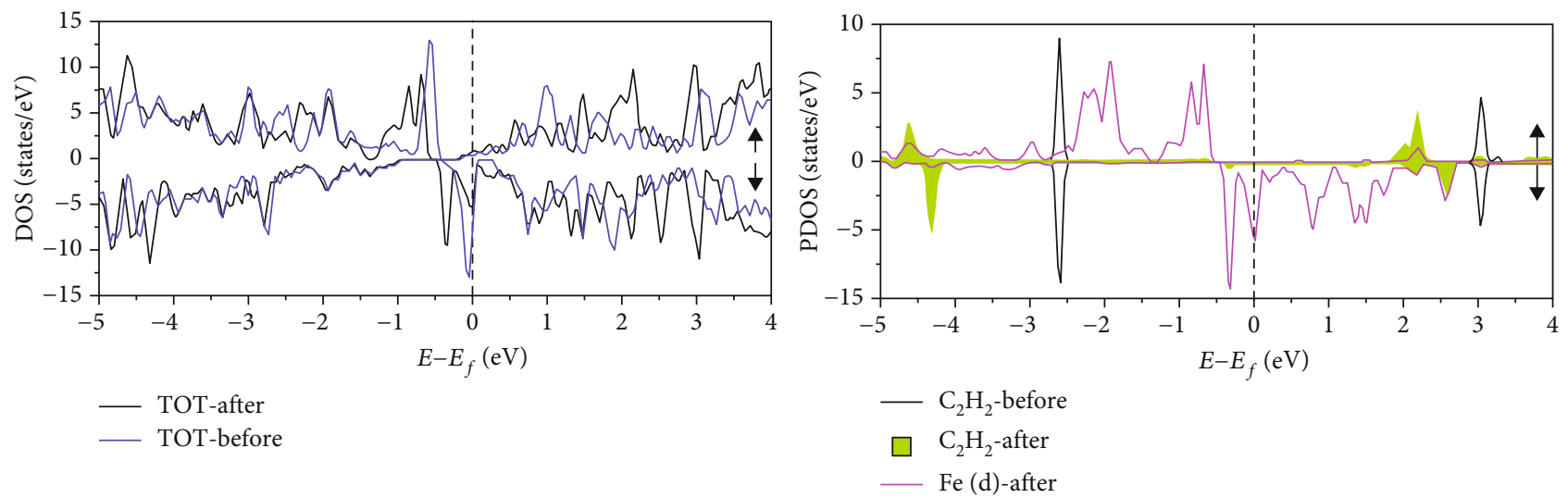

(b)

Figure 3: The density of states (DOS) of $\mathrm{FeN}_{3}$-gra with (a) $\mathrm{C}_{2} \mathrm{H}_{2}$ and (b) $\mathrm{H}_{2} \mathrm{~S}$ adsorbed on it. The figures on the left (right) indicate the corresponding total (partial) DOS. The "before" and "after" indicate the states before and after gas adsorption. The arrow up and arrow down indicate the spin up and spin down states, respectively.

The changed band gap is particularly interesting, which is beneficial for the application in the gas sensor for $\mathrm{H}_{2} \mathrm{~S}$.

3.3. The Adsorption Properties of $\mathrm{SO}_{2}$ and $\mathrm{SO}_{3}$. The adsorption configurations of $\mathrm{SO}_{2}$ and $\mathrm{SO}_{3}$ after full optimization are displayed in Figures S2 (c) and S2 (d). Table S1 displays the adsorption energies, charge transfer, adsorption distance between gas molecules and $\mathrm{FeN}_{3}$-gra, adsorption height, and magnetic moments. For $\mathrm{SO}_{2}$ adsorption, $\mathrm{SO}_{2}$ tends to bind $\mathrm{Fe}$ atom with $\mathrm{O}$ atoms (see Figure S2 (c)), which agrees with the situation of Ti-doped graphene $[44,45]$. Unlike $\mathrm{H}_{2} \mathrm{~S}$, the $\mathrm{N}$ doping can effectively enhance the adsorption of $\mathrm{SO}_{2}$ with an increased adsorption energy of $0.25 \mathrm{eV}$. The length of $\mathrm{Fe}-\mathrm{O}$ bond is $1.97 \AA$, and the angle of $\mathrm{SO}_{2}$ has decreased to $98.1^{\circ}$ after adsorption. Compared to free $\mathrm{SO}_{2}$ molecule, the $\mathrm{S}-\mathrm{O}$ bond has enlarged about $0.11 \AA$, indicating a decreased density of S-O bonds. In comparison, $\mathrm{SO}_{3}$ exhibits an enhanced adsorption strength than $\mathrm{SO}_{2}$ with an adsorption energy of $3.30 \mathrm{eV}\left(E_{\mathrm{ad}}\left[\mathrm{SO}_{2}\right]=1.25 \mathrm{eV}\right)$. This adsorption strength is much larger than the results reported in the pioneering works on Fe-gra $[40,45]$. Thus, the enhancement effect of $\mathrm{N}$ doping exhibits much favorable effect for $\mathrm{SO}_{3}$ compared to $\mathrm{SO}_{2}$ situation. The $\mathrm{SO}_{3}$ binds $\mathrm{FeN}_{3}$-gra bidentately with two $\mathrm{O}$ atoms with $\mathrm{Fe}$, and the corresponding $\mathrm{Fe}-\mathrm{O}$ bond length is $1.88 \AA$. One $\mathrm{O}-\mathrm{S}$ bond in $\mathrm{SO}_{3}$ distributes parallel to $\mathrm{FeN}_{3}$-gra surface. Compared to free $\mathrm{SO}_{3}$, the bond angle (length) of O-S-O (S-O) in $\mathrm{SO}_{3}$ has decreased (increased) from $120^{\circ}\left(1.44 \AA\right.$ ) to $44.2^{\circ}$ and $108.7^{\circ}$ (1.63 $\AA$ and $1.46 \AA$ ). These results have demonstrated that the $\mathrm{N}$ doping can effectively enhance the adsorption of $\mathrm{SO}_{2}$ and $\mathrm{SO}_{3}$.

In order to clarify the adsorption of $\mathrm{SO}_{2}$ and $\mathrm{SO}_{3}$ on $\mathrm{FeN}_{3}$-gra, we have also analyzed electric properties including the charge transfer, DOS, and density of spin during the interaction between $\mathrm{FeN}_{3}$-gra and $\mathrm{SO}_{2} / \mathrm{SO}_{3}$ (see Table S2). The $\mathrm{SO}_{2}$ and $\mathrm{SO}_{3}$ are negatively charged with $0.73 \mathrm{e}$ and $1.09 \mathrm{e}$, respectively. The $\mathrm{SO}_{2}$ and $\mathrm{SO}_{3}$ act as the electron acceptor, which agrees with the pioneering works $[1,22$, 40]. In order to describe the process of charge transfer visually, we have also calculated the charge density difference (CDD) (see Figures S3 (c) and S3 (d)). The $\mathrm{CDD}$ demonstrated that the charge mainly accumulates on $\mathrm{O}$ atoms in $\mathrm{SO}_{2} / \mathrm{SO}_{3}$ and $\mathrm{Fe}$ atom in $\mathrm{FeN}_{3}$-gra. Larger charge transfer may cause significant change of conductivity, which is beneficial for improved sensitivity for gas sensing $[46,47]$.

In order to clarify the change of electric properties in detail, we have analyzed the DOS to investigate the 

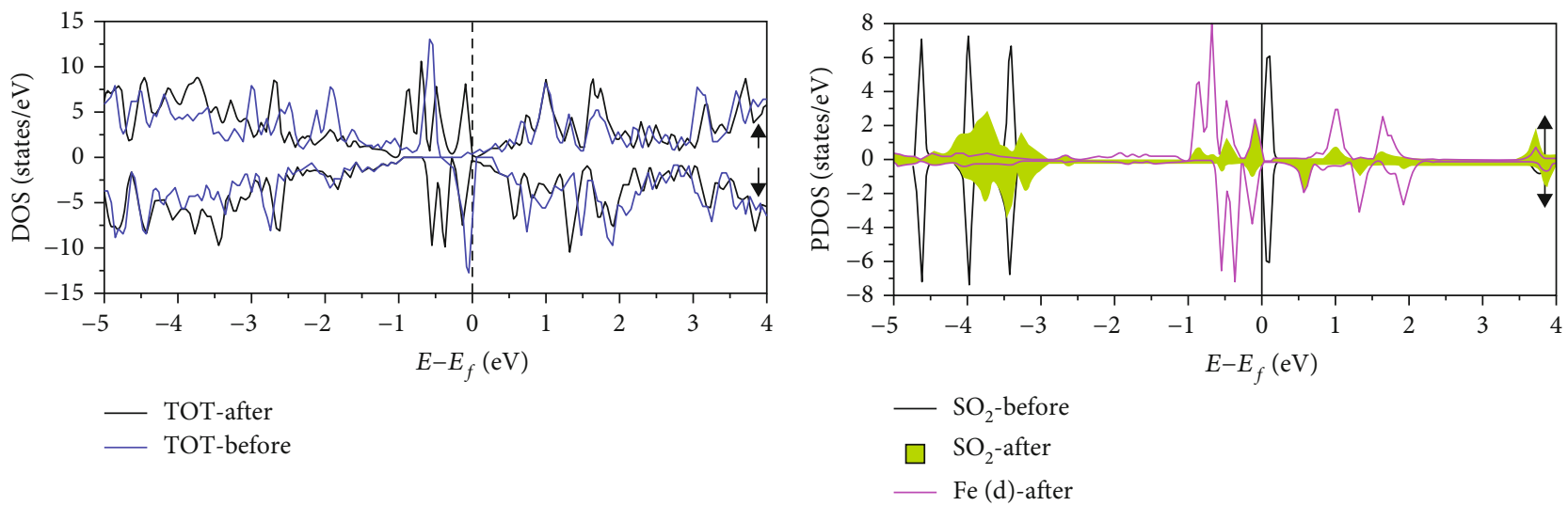

(a)
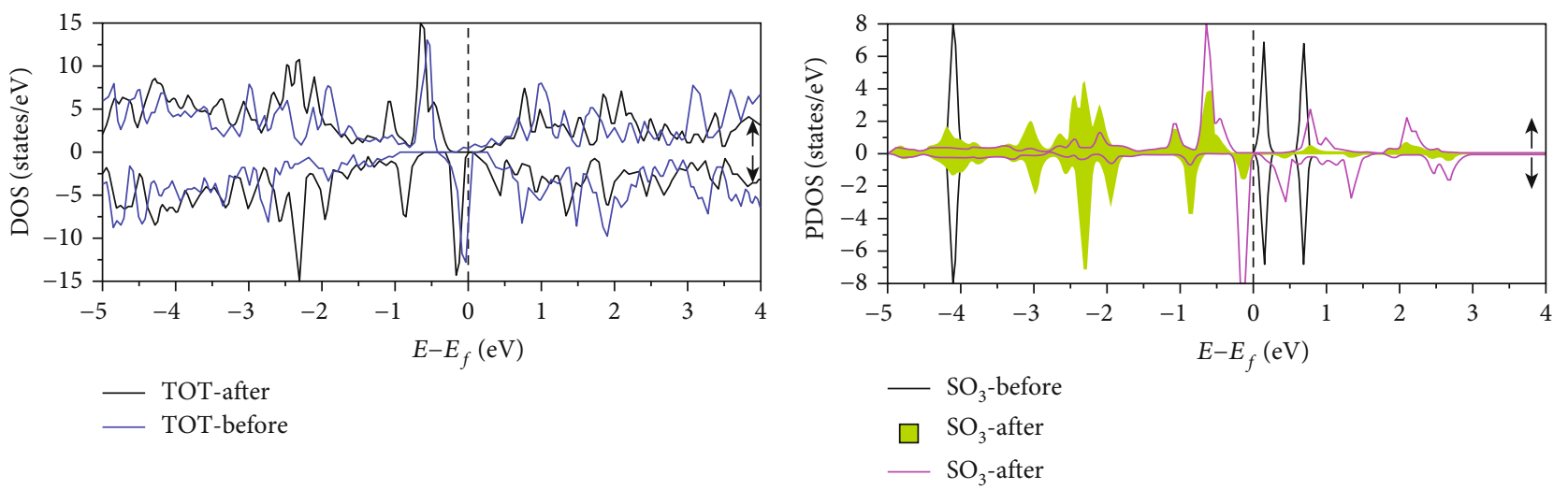

(b)

FIgure 4: The density of states (DOS) of $\mathrm{FeN}_{3}$-gra with (a) $\mathrm{SO}_{2}$ and (b) $\mathrm{SO}_{3}$ adsorbed on it. The figures on the left (right) indicate the corresponding total (partial) DOS. The "before" and "after" indicate the states before and after gas adsorption. The arrow up and arrow down indicate the spin up and spin down states, respectively.
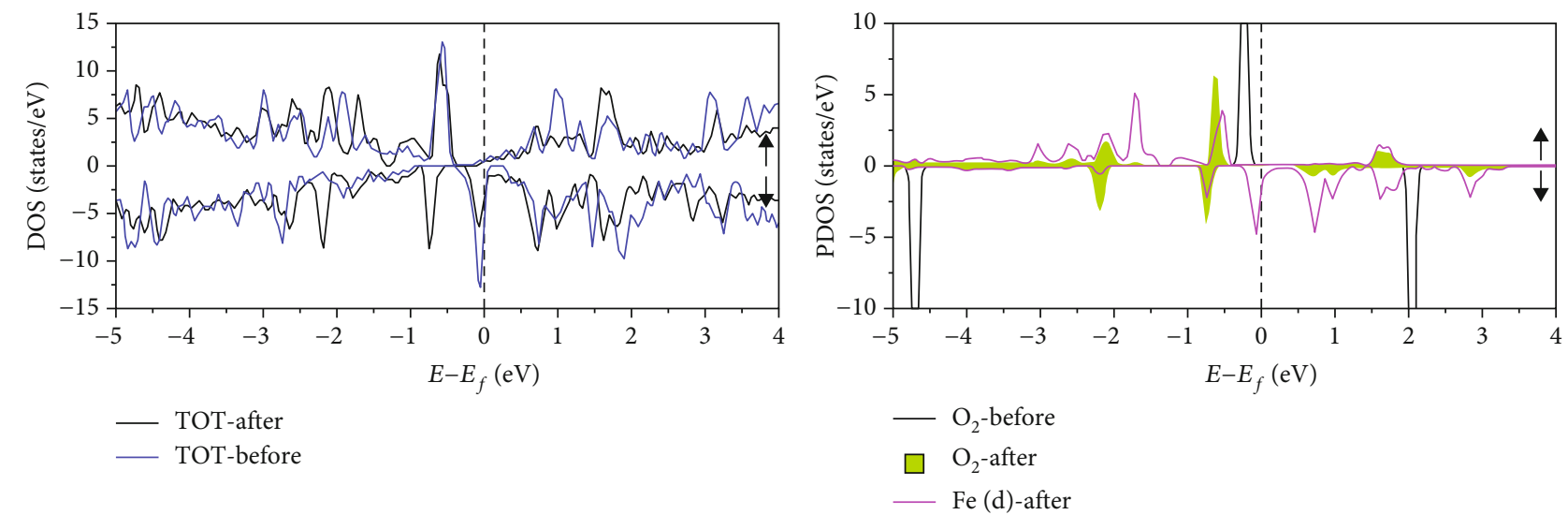

Figure 5: The density of states (DOS) of $\mathrm{FeN}_{3}$-gra with $\mathrm{O}_{2}$ adsorbed on it. The figures on the left (right) indicate the corresponding total (partial) DOS. The "before" and "after" indicate the states before and after gas adsorption. The arrow up and arrow down indicate the spin up and spin down states, respectively.

adsorption properties of $\mathrm{SO}_{2}$ and $\mathrm{SO}_{3}$ (see Figure 4). The DOS of gas molecules has experienced dramatic change caused by the strong interaction between $\mathrm{FeN}_{3}$-gra and $\mathrm{SO}_{2} / \mathrm{SO}_{3}$. The DOS of $\mathrm{SO}_{2}$ ranging from -1.5 to $0 \mathrm{eV}$ has become delocalized after adsorption on $\mathrm{FeN}_{3}$-gra. In addi- tion, the magnetic moment of $\mathrm{FeN}_{3}$-gra has decreased from 3.17 to $-1 \mu \mathrm{B}$ due to the no magnetic character of $\mathrm{SO}_{2}$ and $\mathrm{SO}_{3}$. The spin mainly concentrates on $\mathrm{SO}_{2}$ and $\mathrm{Fe}$ atom with identical spin direction (see Figure S1 (c)). There exists a significant overlap between $\mathrm{Fe}-3 \mathrm{~d}$ states and $\mathrm{SO}_{2}$ at energy 
range of $-1 \sim 0 \mathrm{eV}$ and $1 \sim 1.5 \mathrm{eV}$ (Figure $4(\mathrm{a})$ ). This can also be reflected from the charge overlap in Figure S3 (c), indicating the strong chemical interaction between $\mathrm{Fe}-3 \mathrm{~d}$ and $\mathrm{SO}_{2}$. These characters can also illustrate that a delocalized DOS distribution of $\mathrm{SO}_{2}$ may contribute to enhance the adsorption strength. About $\mathrm{SO}_{3}$, the TDOS ranging from -3 to $0 \mathrm{eV}$ has increased and shifted to lower energy level after $\mathrm{SO}_{3}$ adsorption. Similar to $\mathrm{SO}_{2}$, the adsorption of $\mathrm{SO}_{3}$ can also induce decreased magnetic moments (see Table S2). The formation of spin states of $\mathrm{SO}_{2}$ near Fermi level can hybridize dramatically with Fe. The spin states mainly concentrate on Fe site as shown in Figure $\mathrm{S} 1$ (d). As shown in Table S3, the occupied states in $\mathrm{SO}_{3}$ can lead to increased length of S-O bond, which is verified from charge transfer in Figures S3 (c) and S3 (d). Above all, the analysis of electric and magnetic properties can pave the way for $\mathrm{FeN}_{3}$-gra application in gas sensor and spintronic device.

3.4. The Adsorption Properties of $\mathrm{O}_{2}$. In addition, $\mathrm{O}_{2}$ is also an important gas that is frequently present in the atmosphere. We thus investigated the adsorption behavior of $\mathrm{O}_{2}$ at the end of this article. The most stable configuration of $\mathrm{O}_{2}$ adsorption after optimization is shown in Figure S4. Other information, including the adsorption height, binding distance, charge transfer, adsorption energy, and magnetic moment, is displayed in Table S2. As shown in Figure $\mathrm{S} 4, \mathrm{O}_{2}$ can adsorb on $\mathrm{FeN}_{3}$-gra parallelly with an adsorption energy of $-3.03 \mathrm{eV}$, which is similar to pioneering research [29]. This result has proceeded about 1.5 times of the adsorption energy on FeSV-gra [48]. In addition, the $\mathrm{FeN}_{3}$-gra substrate can activate $\mathrm{O}_{2}$ more effectively than FeSV-gra with a bond length of $1.42 \AA$ of $\mathrm{O}-\mathrm{O}$ bond, compared to the $1.39 \AA$ on FeSV-gra. This character may originate from the enhanced interaction between $\mathrm{O}_{2}$ and $\mathrm{FeN}_{3}$-gra.

In order to clarify the $\mathrm{O}_{2}$ adsorption on $\mathrm{FeN}_{3}$-gra, we have also calculated the electric properties, including charge transfer, DOS, and spin density. The $\mathrm{O}_{2}$ has been negatively charged with -0.77 e by the substrate, indicating the strong interaction between $\mathrm{O}_{2}$ and $\mathrm{FeN}_{3}$-gra. In other words, $\mathrm{O}_{2}$ can act as an electron acceptor. These characters can also be reflected from the charge density difference (Figure S4 (c)): There exists a strong overlap between the charge distribution of $\mathrm{O}_{2}$ and $\mathrm{FeN}_{3}$-gra, indicating a covalent bond. In addition, $\mathrm{O}_{2}$ has been magnetized after adsorption on $\mathrm{FeN}_{3}$-gra as shown in Figure 5: The spin density distributes both on $\mathrm{O}_{2}$ and $\mathrm{FeN}_{3}$-gra. This may derive from the significant hybridization between $\mathrm{O}_{2}$ and Fe-3d orbitals (Figure 5(a)).

\section{Conclusions}

In conclusion, we have investigated a series of gas molecules, including $\mathrm{C}_{2} \mathrm{H}_{2}, \mathrm{H}_{2} \mathrm{~S}, \mathrm{SO}_{2}, \mathrm{SO}_{3}$, and $\mathrm{O}_{2}$, on $\mathrm{FeN}_{3}$-gra. These molecules can interact strongly with $\mathrm{FeN}_{3}$-gra. Particularly, $\mathrm{FeN}_{3}$-gra can adsorb $\mathrm{SO}_{2} / \mathrm{SO}_{3}$ and $\mathrm{O}_{2}$ much strongly than Fe-gra, which mainly originates from $\mathrm{N}$ doping. The strong interaction may induce dramatic change of electric conductivity of $\mathrm{FeN}_{3}$-gra, leading to a high sensitivity for gas sens- ing. Besides, the adsorbed gas molecules can modulate the magnetic property of $\mathrm{FeN}_{3}$-gra effectively. Thus, our results can provide theoretical basement for applications of gas sensing and spintronic devices.

\section{Data Availability}

The data underlying the results presented in the study are available within the manuscript and supplementary materials.

\section{Conflicts of Interest}

All the authors declare no conflict of interest.

\section{Acknowledgments}

This research was supported by the Transformation of Scientific and Technological Achievements Programs of Higher Education Institutions in Shanxi (No. 2020CG032), Cultivation Plan of Young Scientific Researchers in Higher Education Institutions of Shanxi Province, and the Fund for Shanxi "1331 Project".

\section{Supplementary Materials}

The supporting information is available free of charge on the Hindawi website publications at DOI. Table S1: the comparison of parameters between our work and the pioneering studies for $\mathrm{FeN}_{3}$-gra substrate: the length of $\mathrm{Fe}-\mathrm{N}$ bond ( $d$ $/ \AA)$, the uplift height of $\mathrm{Fe}(h / \AA)$, binding energy of $\mathrm{Fe}\left(E_{\mathrm{b}}\right.$ $[\mathrm{Fe}] / \mathrm{eV})$, charge transfer between $\mathrm{Fe}$ and graphene (CT/e), and the magnetic moment of the system $(M / \mu \mathrm{B})$. Table S2: the parameters of gas molecules, including $\mathrm{C}_{2} \mathrm{H}_{2}, \mathrm{H}_{2} \mathrm{~S}, \mathrm{SO}_{2}$, and $\mathrm{SO}_{3}$, adsorbed $\mathrm{FeN}_{3}$-gra: the length of $\mathrm{Fe}-\mathrm{N}$ bond ( $d$ $/ \AA)$, the uplift height of $\mathrm{Fe}(h / \AA)$, the binding energy of $\mathrm{Fe}$ $\left(E_{\mathrm{b}}[\mathrm{Fe}] / \mathrm{eV}\right)$, the adsorption energy of gas molecules $\left(E_{\mathrm{ad}}\right.$ $(\mathrm{eV})$, the charge transfer between gas molecules and $\mathrm{FeN}_{3}$ gra (CT/e), and the magnetic moment of the system ( $M$ $/ \mu \mathrm{B})$. Table S3: the geometric configurations of different systems: the length $(d / \AA)$ and angle $\left(\theta /^{\circ}\right)$ of various bonds in the gas molecules in separated and adsorbed states. Figure S1: the spin density of gas molecules, including (a) $\mathrm{C}_{2} \mathrm{H}_{2}$, (b) $\mathrm{H}_{2} \mathrm{~S}$, (c) $\mathrm{SO}_{2}$, and (d) $\mathrm{SO}_{3}$, on $\mathrm{FeN}_{3}$-gra (spin up (yellow) and spin down (cyan); isosurface value: $0.01 \mathrm{e} / \mathrm{Bohr}^{3}$ ). Figure S2: the adsorption configurations of gas molecules, including (a) $\mathrm{C}_{2} \mathrm{H}_{2}$, (b) $\mathrm{H}_{2} \mathrm{~S}$, (c) $\mathrm{SO}_{2}$, and (d) $\mathrm{SO}_{3}$, on $\mathrm{FeN}_{3}$-gra. Figure S3: the charge density difference (CDD) of (a) $\mathrm{C}_{2} \mathrm{H}_{2}-\mathrm{FeN}_{3}$ gra, (b) $\mathrm{H}_{2} \mathrm{~S}-\mathrm{FeN}_{3}$-gra, (c) $\mathrm{SO}_{2}-\mathrm{FeN}_{3}$-gra, and (d) $\mathrm{SO}_{3}$ $\mathrm{FeN}_{3}$-gra. GN. The accumulation and depletion of electrons are represented by the yellow and cyan regions, respectively (isosurface value: $0.003 \mathrm{e} / \mathrm{Bohr}^{3}$ ). Figure S4: (a) the adsorption configuration of $\mathrm{O}_{2}$ on $\mathrm{FeN}_{3}$-gra. (b) The spin density of $\mathrm{FeN}_{3}$-gra with $\mathrm{O}_{2}$ adsorbed on it (spin up (yellow) and spin down (cyan); isosurface value: $0.01 \mathrm{e} / \mathrm{Bohr}^{3}$ ). (c) The charge density difference of $\mathrm{FeN}_{3}$-gra with $\mathrm{O}_{2}$ adsorbed on it. The accumulation and depletion of electrons are represented by the yellow and cyan regions, respectively (isosurface value: $0.003 \mathrm{e} / \mathrm{Bohr}^{3}$ ). (Supplementary Materials) 


\section{References}

[1] A. Shokuhi Rad, M. Esfahanian, S. Maleki, and G. Gharati, "Application of carbon nanostructures toward $\mathrm{SO}_{2}$ and $\mathrm{SO}_{3}$ adsorption: a comparison between pristine graphene and $\mathrm{N}$ doped graphene by DFT calculations," Journal of Sulfur Chemistry, vol. 37, no. 2, pp. 176-188, 2016.

[2] Y. Zhou, Y. Wang, and Y. Guo, "Cuprous oxide nanowires/ nanoparticles decorated on reduced graphene oxide nanosheets: sensitive and selective $\mathrm{H}_{2} \mathrm{~S}$ detection at low temperature,” Materials Letters, vol. 254, pp. 336-339, 2019.

[3] A. S. Rad, "Adsorption of $\mathrm{C}_{2} \mathrm{H}_{2}$ and $\mathrm{C}_{2} \mathrm{H}_{4}$ on Pt-decorated graphene nanostructure: ab-initio study," Synthetic Metals, vol. 211, pp. 115-120, 2016.

[4] T. Wagner, S. Haffer, C. Weinberger, D. Klaus, and M. Tiemann, "Mesoporous materials as gas sensors," Chemical Society Reviews, vol. 42, no. 9, pp. 4036-4053, 2013.

[5] L. Yin, H. Wang, L. Li, H. Li, D. Chen, and R. Zhang, "Microwave-assisted preparation of hierarchical CuO@rGO nanostructures and their enhanced low-temperature $\mathrm{H}_{2} \mathrm{~S}$-sensing performance," Applied Surface Science, vol. 476, pp. 107-114, 2019.

[6] M. F. Camellone and S. Fabris, "Reaction mechanisms for the $\mathrm{CO}$ oxidation on $\mathrm{Au} / \mathrm{CeO}_{2}$ catalysts: activity of substitutional $\mathrm{Au}_{3}{ }^{+} / \mathrm{Au}^{+}$cations and deactivation of supported $\mathrm{Au}^{+}$adatoms," Journal of the American Chemical Society, vol. 131, no. 30, pp. 10473-10483, 2009.

[7] A. Shokuhi Rad and D. Zareyee, "Adsorption properties of $\mathrm{SO}_{2}$ and $\mathrm{O}_{3}$ molecules on Pt-decorated graphene: a theoretical study," Vacuum, vol. 130, pp. 113-118, 2016.

[8] M. Chu, X. Liu, Y. Sui, J. Luo, and C. Meng, "Unique reactivity of transition metal atoms embedded in graphene to $\mathrm{CO}, \mathrm{NO}$, $\mathrm{O}_{2}$ and $\mathrm{O}$ adsorption: a first-principles investigation," Molecules, vol. 20, no. 10, pp. 19540-19553, 2015.

[9] W. Yuan and G. Shi, "Graphene-based gas sensors," Journal of Materials Chemistry A, vol. 1, pp. 10078-10091, 2013.

[10] Y. H. Wu, T. Yu, and Z. X. Shen, “Two-dimensional carbon nanostructures: fundamental properties, synthesis, characterization, and potential applications," Journal of Applied Physics, vol. 108, no. 7, 2010.

[11] A. K. Geim and K. S. Novoselov, "The rise of graphene," Nanoscience and Technology: A Collection of Reviews from Nature Journals, pp. 11-19, 2009.

[12] L. Kong, A. Enders, T. S. Rahman, and P. A. Dowben, "Molecular adsorption on graphene," Journal of Physics-Condensed Matter, vol. 26, no. 44, article 443001, 2014.

[13] O. Leenaerts, B. Partoens, and F. M. Peeters, "Adsorption of $\mathrm{H}_{2} \mathrm{O}, \mathrm{NH}_{3}, \mathrm{CO}, \mathrm{NO}_{2}$, and $\mathrm{NO}$ on graphene: a first-principles study," Physical Review B, vol. 77, no. 12, article 125416, 2008.

[14] O. Leenaerts, B. Partoens, and F. M. Peeters, "Adsorption of small molecules on graphene," Microelectronics Journal, vol. 40, no. 4-5, pp. 860-862, 2009.

[15] M. Pumera, A. Ambrosi, A. Bonanni, E. L. K. Chng, and H. L. Poh, "Graphene for electrochemical sensing and biosensing," TrAC Trends in Analytical Chemistry, vol. 29, no. 9, pp. 954965, 2010.

[16] J. Kong, N. R. Franklin, C. Zhou et al., "Nanotube molecular wires as chemical sensors," Science, vol. 287, pp. 622-625, 2000.

[17] H. J. Yoon, D. H. Jun, J. H. Yang, Z. Zhou, S. S. Yang, and M. M.-C. Cheng, "Carbon dioxide gas sensor using a graphene sheet," Sensors and Actuators B: Chemical, vol. 157, no. 1, pp. 310-313, 2011.

[18] F. Yang, D. Deng, X. Pan, Q. Fu, and X. Bao, "Understanding nano effects in catalysis," National Science Review, vol. 2, no. 2, pp. 183-201, 2015.

[19] K. Jiang, S. Siahrostami, A. J. Akey et al., "Transition-metal single atoms in a graphene shell as active centers for highly efficient artificial photosynthesis," Chem, vol. 3, no. 6, pp. 950-960, 2017.

[20] X. Gao, Y. Zhou, Y. Tan, B. Yang, Z. Cheng, and Z. Shen, "Single Mo atoms supported on N-doped carbon with N/C edgesite for enhanced electrochemical hydrogen evolution," International Journal of Hydrogen Energy, vol. 44, no. 29, pp. 14861-14868, 2019.

[21] L. Ma, J.-M. Zhang, K.-W. Xu, and V. Ji, “A first-principles study on gas sensing properties of graphene and Pd-doped graphene," Applied Surface Science, vol. 343, pp. 121-127, 2015.

[22] D. Cortés-Arriagada, N. Villegas-Escobar, and D. E. Ortega, "Fe-doped graphene nanosheet as an adsorption platform of harmful gas molecules $\left(\mathrm{CO}, \mathrm{CO}_{2}, \mathrm{SO}_{2}\right.$ and $\left.\mathrm{H}_{2} \mathrm{~S}\right)$, and the $\mathrm{CO}$-adsorption in $\mathrm{O}_{2}$ environments," Applied Surface Science, vol. 427, pp. 227-236, 2018.

[23] L. Zhang, C. Chang, C.-W. Hsu, C.-W. Chang, and S.-Y. Lu, "Hollow nanocubes composed of well-dispersed mixed metal-rich phosphides in N-doped carbon as highly efficient and durable electrocatalysts for the oxygen evolution reaction at high current densities," Journal of Materials Chemistry A, vol. 5, pp. 19656-19663, 2017.

[24] P. Chen, T. Zhou, L. Xing et al., "Atomically dispersed ironnitrogen species as electrocatalysts for bifunctional oxygen evolution and reduction reactions," Angewandte Chemie, vol. 56, pp. 610-614, 2017.

[25] H. Jin, J. Wang, D. Su, Z. Wei, Z. Pang, and Y. Wang, "In situ cobalt-cobalt oxide/ $\mathrm{N}$-doped carbon hybrids as superior bifunctional electrocatalysts for hydrogen and oxygen evolution," Journal of the American Chemical Society, vol. 137, no. 7, pp. 2688-2694, 2015.

[26] X. Qiao, S. Liao, R. Zheng, Y. Deng, H. Song, and L. Du, "Cobalt and nitrogen codoped graphene with inserted carbon nanospheres as an efficient bifunctional electrocatalyst for oxygen reduction and evolution," ACS Sustainable Chemistry \& Engineering, vol. 4, no. 8, pp. 4131-4136, 2016.

[27] L. Zhang, W. Liu, Y. Dou, Z. Du, and M. Shao, "The role of transition metal and nitrogen in metal-N-C composites for hydrogen evolution reaction at universal pHs," The Journal of Physical Chemistry C, vol. 120, no. 51, pp. 29047-29053, 2016.

[28] X. F. Li, Q. K. Li, J. Cheng et al., "Conversion of dinitrogen to ammonia by $\mathrm{FeN}_{3}$-embedded graphene," Journal of the American Chemical Society, vol. 138, no. 28, pp. 8706-8709, 2016.

[29] Z. Liu, D. Zhang, G. Jin, and W. Yang, "Catalytic oxidation degradation of formaldehyde on $\mathrm{FeN}_{3}$-graphene surface: a DFT study," Applied Surface Science, vol. 534, article 147594, 2020.

[30] J. F. G. Kresse, "Efficiency of ab-initio total energy calculations for metals and semiconductors using a plane-wave basis set," Computational Materials Science, vol. 6, no. 1, pp. 15-50, 1996.

[31] J. F. G. Kresse, "Efficient iterative schemes for ab initio totalenergy calculations using a plane-wave basis set," Physical Review B, vol. 54, no. 16, pp. 11169-11186, 1996. 
[32] J. P. Perdew, M. Ernzerhof, and K. Burke, "Rationale for mixing exact exchange with density functional approximations," The Journal of Chemical Physics, vol. 105, pp. 9982-9985, 1996.

[33] J. P. Perdew, K. Burke, and M. Ernzerhof, "Generalized gradient approximation made simple," Physical Review Letters, vol. 77, no. 18 , pp. 3865-3868, 1996.

[34] G. K. D. Joubert, "From ultrasoft pseudopotentials to the projector augmented-wave method," Physical Review B, vol. 59, no. 3, pp. 1758-1775, 1999.

[35] S. Grimme, J. Antony, S. Ehrlich, and H. Krieg, "A consistent and accurateab initioparametrization of density functional dispersion correction (DFT-D) for the 94 elements $\mathrm{H}-\mathrm{Pu}$," Journal of Chemical Physics, vol. 132, no. 15, article 154104, 2010.

[36] T. Xie, P. Wang, C. Tian et al., "The adsorption behavior of gas molecules on $\mathrm{Co} / \mathrm{N}$ co-doped graphene," Molecules, vol. 26, no. 24, 2021.

[37] W. Tang, E. Sanville, and G. Henkelman, "A grid-based Bader analysis algorithm without lattice bias," Journal of Physicscondensed Matter, vol. 21, no. 8, article ???, 2009.

[38] K. Momma and F. Izumi, "VESTA 3for three-dimensional visualization of crystal, volumetric and morphology data," Journal of Applied Crystallography, vol. 44, no. 6, pp. 12721276, 2011.

[39] S. Kattel, P. Atanassov, and B. Kiefer, "Stability, electronic and magnetic properties of in-plane defects in graphene: a firstprinciples study," The Journal of Physical Chemistry C, vol. 116, no. 14, pp. 8161-8166, 2012.

[40] Z. Gao, W. Yang, X. Ding, G. Lv, and W. Yan, "Support effects in single atom iron catalysts on adsorption characteristics of toxic gases $\left(\mathrm{NO}_{2}, \mathrm{NH}_{3}, \mathrm{SO}_{3}\right.$ and $\left.\mathrm{H}_{2} \mathrm{~S}\right)$," Applied Surface Science, vol. 436, pp. 585-595, 2018.

[41] A. V. Krasheninnikov, P. O. Lehtinen, A. S. Foster, P. Pyykko, and R. M. Nieminen, "Embedding transition-metal atoms in graphene: structure, bonding, and magnetism," Physical Review Letters, vol. 102, no. 12, article 126807, 2009.

[42] X. F. Li, K. Y. Lian, Q. Qiu, and Y. Luo, "Half-filled energy bands induced negative differential resistance in nitrogendoped graphene," Nanoscale, vol. 7, no. 9, pp. 4156-4162, 2015.

[43] Y. Gui, X. Peng, K. Liu, and Z. Ding, "Adsorption of $\mathrm{C}_{2} \mathrm{H}_{2}$, $\mathrm{CH}_{4}$ and $\mathrm{CO}$ on $\mathrm{Mn}$-doped graphene: atomic, electronic, and gas-sensing properties," Physica E: Low-dimensional Systems and Nanostructures, vol. 119, article 113959, 2020.

[44] H. P. Zhang, X. G. Luo, X. Y. Lin, X. Lu, Y. Leng, and H. T. Song, "Density functional theory calculations on the adsorption of formaldehyde and other harmful gases on pure, Tidoped, or N-doped graphene sheets," Applied Surface Science, vol. 283, pp. 559-565, 2013.

[45] M. J. Harrison, D. P. Woodruff, and J. Robinson, "Density functional theory investigation of the structure of $\mathrm{SO}_{2}$ and $\mathrm{SO}_{3}$ on $\mathrm{Cu}(111)$ and $\mathrm{Ni}(111)$," Surface Science, vol. 600, no. 9, pp. 1827-1836, 2006.

[46] J. Y. Jiayu Dai and P. Giannozzi, "Gas adsorption on graphene doped with ' $1 \mathrm{Al}$, and S: a theoretical study," Applied Physics Letters, vol. 95, no. 23, 2009.
[47] X. Gao, Y. Zhou, S. Liu, Y. Tan, Z. Cheng, and Z. Shen, "FeN ${ }_{3}$ embedded carbon as an efficient sorbent for mercury adsorption: a theoretical study," Chemical Engineering Journal, vol. 374, pp. 1337-1343, 2019.

[48] W. Yang, Z. Gao, X. Liu, X. Li, X. Ding, and W. Yan, "Singleatom iron catalyst with single-vacancy graphene-based substrate as a novel catalyst for NO oxidation: a theoretical study," Catalysis Science \& Technology, vol. 8, no. 16, pp. 4159-4168, 2018. 